\title{
RESEARCH ARTICLE Recombinant Sendai virus provides a highly efficient gene transfer into human cord blood-derived hematopoietic stem cells
}

\author{
$\mathrm{CH} \mathrm{Jin}^{1}$, K Kusuhara ${ }^{1}$, Y Yonemitsu ${ }^{2}$, A Nomura ${ }^{1}$, S Okano ${ }^{2}$, H Takeshita ${ }^{2}, \mathrm{M} \mathrm{Hasegawa}^{3}$, \\ K Sueishi ${ }^{2}$ and T Hara ${ }^{1}$ \\ ${ }^{1}$ Department of Pediatrics, Graduate School of Medical Sciences, Kyushu University, Fukuoka, Japan; ${ }^{2}$ Department of Pathology, \\ Division of Pathophysiological and Experimental Pathology, Graduate School of Medical Sciences, Kyushu University, Fukuoka, Japan; \\ and ${ }^{3}$ DNAVEC Research Inc. Tsukuba, Ibaraki, Japan
}

\begin{abstract}
Hematopoietic stem cells (HSCs) are a promising target for gene therapy, however, the low efficiencies of gene transfer using currently available vectors face practical limitations. We have recently developed a novel and efficient gene transfer agent, namely recombinant Sendai virus (SeV), and we have here characterized SeV-mediated gene transfer to human cord blood (CB) HSCs and primitive progenitor cells $(P P C)$ using the jelly fish green fluorescent protein (GFP) gene. Even at a relatively low titer (10 multiplicity of infections), SeV achieved highly efficient GFP expression in $C B C D 34^{+}$cells $(85.5 \pm 5.8 \%)$, as well as more immature $C B$ progenitor cells, $C D 34^{+} A C 133^{+}(88.2 \pm 3.7 \%)$ and
\end{abstract}

CD34+CD38- $(84.6 \pm 5.7 \%)$ cells, without cytokines prestimulation, that was a clear contrast to the features of gene transfer using retroviruses. SeV-mediated gene transfer was not seriously affected by the cell cycle status. In vitro cell differentiation studies revealed that gene transfer occurred in progenitor cells of all lineages (GM-CFU, $73.0 \pm 11.1 \%$; BFU-E, 24.7 \pm 4.0\%; Mix-CFU, $59 \pm 4.0 \%$; and total, $50.0 \pm 7.0 \%)$. These findings show that SeV could prove to be a promising vector for efficient gene transfer to CB HSCs, while preserving their ability to reconstitute the entire hematopoietic series.

Gene Therapy (2003) 10, 272-277. doi:10.1038/sj.gt.3301877

Keywords: Recombinant Sendai virus; cord blood; hematopoietic stem cells; CD34+ cells; gene therapy

\section{Introduction}

Gene therapy targeting hematopoietic stem cells (HSCs) holds promise to treat a number of genetic and acquired diseases. HSCs are an ideal target on this purpose, because these progenitors can reconstitute the entire hematopoietic system in a recipient during a lifetime. Successful application of stem-cell-based gene therapies to treat blood system disorders requires an efficient gene delivery system, long-term reconstitution of hematopoiesis from transduced HSCs, and stable expression of the therapeutic gene(s) in the affected blood cell lineages. Although a number of experimental studies have been done for gene transfer to HSCs, a major limitation of currently available gene transfer vectors is the low gene transfer efficiency.

We recently developed a novel viral vector for efficient gene transfer, namely recombinant Sendai virus (SeV), through which there is an efficient gene transfer into several systems, including airway epithelial cells, ${ }^{1}$ vascular tissue, ${ }^{2}$ skeletal muscle, ${ }^{3}$ as well as synovial cells. ${ }^{4} \mathrm{SeV}$, a member of the family Paramyxoviridae, has a non-segmented negative-strand RNA genome and

Correspondence: K Kusuhara, Department of Pediatrics, Graduate School of Medical Sciences, Kyushu University, 3-1-1, Maidashi, Higashi-ku, Fukuoka 812-8582, Japan

Received 9 April 2002; accepted 1 August 2002 makes use of sialic acid residue on surface glycoprotein or asialoglycoprotein present on most cell types as a receptor. ${ }^{5}$ As $\mathrm{SeV}$ uses a cytoplasmic transcription system, it can mediate gene transfer to a cytoplasmic location. ${ }^{6}$ There are technical advantages in the use of recombinant $\mathrm{SeV}$ as gene therapy vector. First, the activity of $\mathrm{SeV}$ particles is stable and can be easily concentrated to high titers, which is in clear contrast to the features of retroviral vectors. Second, and most importantly, the modalities of target cell processing and viral transduction are technically non-demanding and feasible in clinical situations that require tranduction into large numbers of target cells.

Since characteristics of gene transfer with $\mathrm{SeV}$ to HSCs have not been documented yet, we analyzed the efficiency and transgene expression in SeVmediated gene transfer to cord blood (CB) hematopoietic precursor and progenitor cells to test whether $\mathrm{SeV}$ could overcome current limitations in gene transfer for HSC.

\section{Results}

Transduction efficiency in $C B C D 34^{+}$cells

We first evaluated the efficiency of recombinant $\mathrm{SeV}$ vector-mediated gene transfer to $\mathrm{CB} \mathrm{CD} 34^{+}$cells. Evaluated based on green fluorescent protein (GFP) 

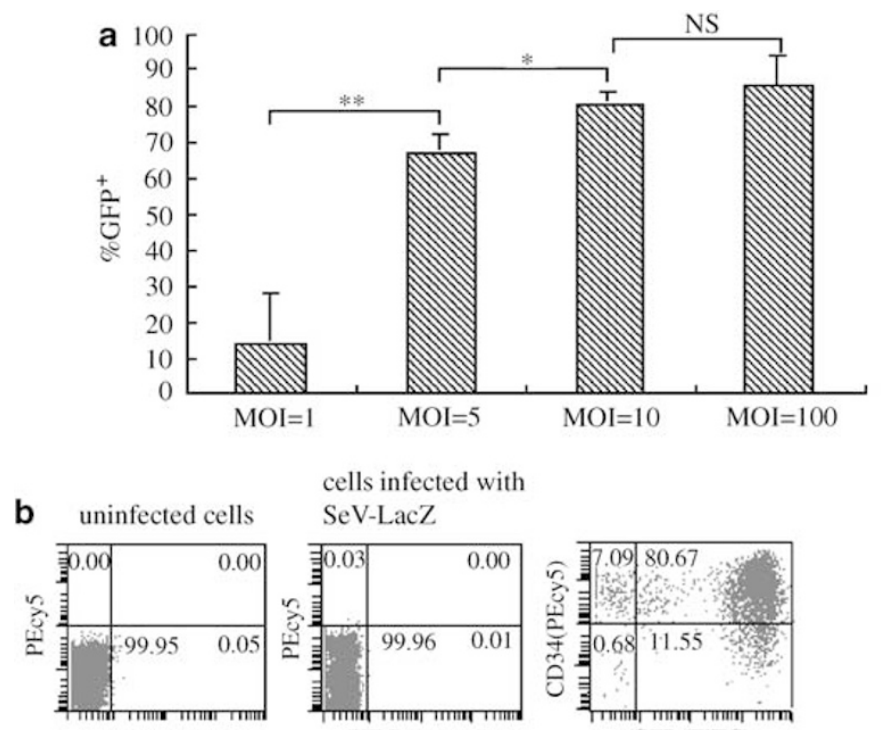

cells infected with

SeV-LacZ
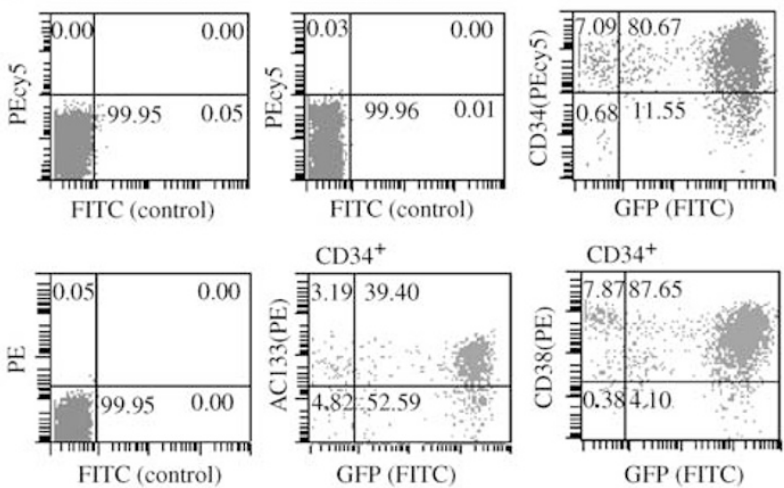

GFP (FITC)

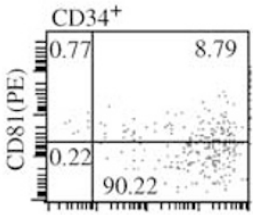

GFP (FITC)

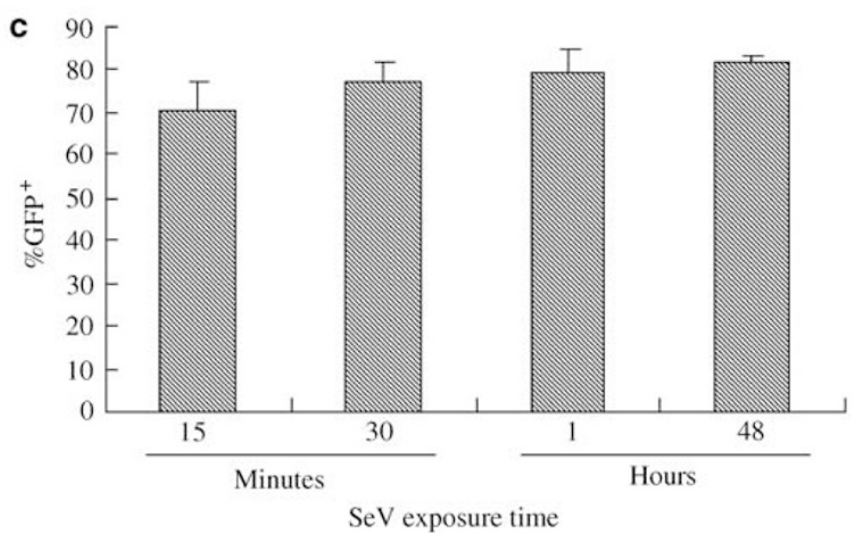

Figure 1 (a) SeV-mediated, dose-dependent GFP gene transfer to human CB-derived CD34 ${ }^{+}$cells. After enrichment of CD34 cells using microbeads bound to anti-human CD34 antibody, the vector solution with SeV-GFP at each titer was simply added to the cell suspension. Forty-eight hours later, the cells were subjected to flow-cytometric analyses. The bar graph indicates the dose-dependent increase in gene transfer efficiency, and the efficiency almost reached its peak at 10 multiplicity of infections (MOI=10). Data from four CB samples, each in triplicate, are shown as mean \pm standard deviation values. ${ }^{* *} P<0.01$. ${ }^{*} P<0.05$. NS: not significant. (b) Flow-cytometric analysis indicating SeV-mediated, efficient gene transfer to immature CD34 ${ }^{+}$ precursors $\left(C D 34^{+} A C 133^{+}, C D 34+C D 38^{-}\right.$and $C D 34^{+} C D 81^{+}$cells). Forty-eight hours after gene transfer at MOI=10 with SeV-GFP to each subpopulation, the cells were subjected to flow-cytometric analysis. The experiment was done in triplicate, with consistent results. (c). Effect of vector exposure time on SeV-mediated gene transfer into enriched $C B C D 34^{+}$cells. Enriched $C B C D 34^{+}$cells were exposed to SeV-GFP (MOI=10) by adding vector solution, and the cells were washed twice with fresh media after the respective incubation time. Forty-eight hours after the addition of vector solution, cells were subjected to flow-cytometric analysis. Data, each in triplicate, are shown as mean \pm standard deviation values.

expression, using flow cytometry on day 2, CB CD34 ${ }^{+}$cells showed a dose-dependent, highly efficient GFP gene transduction rate with a plateau at the titer of 10 multiplicity of infections (MOI) and over (Figure 1a). Transduction in the following experiments was thus done at the titer of 10 MOI. As shown in Figure 1b, highly efficient expression of transgene on day 2 was observed not only in CB CD $34^{+}$cells $(85.5 \pm 5.8 \%)$, but also in more immature $\mathrm{CB}$ progenitors, $\mathrm{CD} 34^{+} \mathrm{AC} 133^{+}$
$(88.2 \pm 3.7 \%)$ and $\mathrm{CD} 34^{+} \mathrm{CD} 38^{-}(84.6 \pm 5.7 \%)$ cells, and multilymphoid progenitor, $\mathrm{CD} 34^{+} \mathrm{CD} 81^{+}$cells $(87.3 \pm 4.7 \%)$.

Next, we evaluated the effect of vector exposure time on SeV-mediated gene transfer efficiency at the titer of $\mathrm{MOI}=10$. The GFP gene expression on day 2 was not markedly affected by vector-cell interaction time, and even a 30-min exposure led to a GFP expression level comparable to that seen with a 48-h exposure (Figure 1C). 


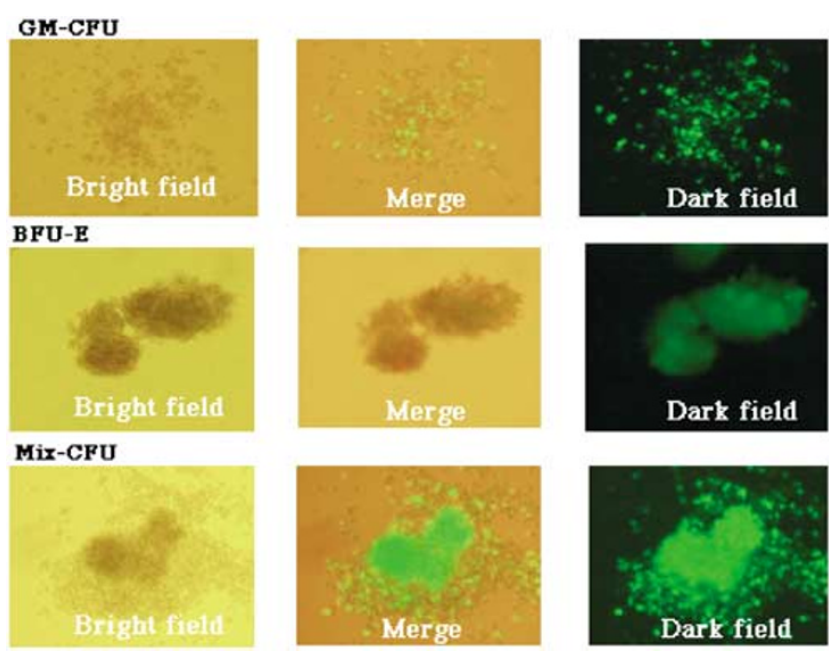

Figure 2 Colony assays for human cord blood-derived CD34 ${ }^{+}$cells treated by SeV-GFP. Representative fluorescence microscopic data on GFP expression of colonies from $\mathrm{CB} C D 34^{+}$cells. All cell lineages, including GM-CFU (upper series) and BFU-E (middle series) as well as Mix-CFU (bottom series), showed efficient GFP expression.

\section{Transduction of CB-derived CFUs}

To evaluate the gene transfer potential of the $\mathrm{SeV}$ vector to colony-forming $\mathrm{CB}$ progenitors, colony assays were done for $\mathrm{CB} \mathrm{CD} 34^{+}$cells exposed to $\mathrm{SeV}$. GFP expression on day 14 was analyzed in colonies derived from committed CFUs. Highly efficient GFP expression was observed in progenitor cells of all lineages (GM-CFU, $73.0 \pm 11.1 \%$; BFU-E, $24.7 \pm 4.0 \%$; Mix-CFU, $59 \pm 4.0 \%$; Total, $50.0 \pm 7.0 \%$ ) (Figure 2 and Table 1). Although the total number of colonies derived from SeV-treated CB $\mathrm{CD} 4^{+}$cells tended to be smaller $(P=0.09)$ than those from control CB CD34 ${ }^{+}$cells, the numbers of GM-CFU, BFU-E and Mix-CFU colonies were almost the same (Table 1), thereby suggesting that the transduction procedure did not significantly impair growth of these colonies.

\section{Efficiency of transduction relative to cell cycle status}

To investigate the dependency of transduction efficiency with $\mathrm{SeV}$ on the cell cycle phases, we analyzed the
Table 1 Quantitative analysis of GFP expression in colony-forming cells (CFCs) from cord blood CD $34^{+}$cells by progenitor colony assay

\begin{tabular}{|c|c|c|c|c|c|}
\hline & Total & GM-CFU & BFU-E & Mix-CFU \\
\hline & & $\begin{array}{c}\mathrm{GFP}^{+} / \text {total } \\
(\%)\end{array}$ & $\begin{array}{c}\mathrm{GFP}^{+} / \text {total } \\
(\%)\end{array}$ & $\begin{array}{c}\mathrm{GFP}^{+} / \text {total } \\
(\%)\end{array}$ & $\begin{array}{c}\mathrm{GFP}^{+} / \text {total } \\
(\%)\end{array}$ \\
\hline \multirow[t]{2}{*}{ CB1 } & $\mathrm{SeV}+$ & $83 / 198$ (41.9) & $51 / 72(70.8)$ & 16/81 (19.8) & $3 / 5(60)$ \\
\hline & $\mathrm{SeV}-$ & $0 / 270$ & $0 / 72$ & $0 / 98$ & $0 / 10$ \\
\hline \multirow[t]{2}{*}{ CB2 } & $\mathrm{SeV}+$ & $138 / 258(53.5)$ & $75 / 90(83.3)$ & $36 / 123(29.3)$ & $6 / 11(54.5)$ \\
\hline & $\mathrm{SeV}-$ & $0 / 320$ & 0/150 & 0/110 & $0 / 6$ \\
\hline \multirow[t]{2}{*}{ CB3 } & $\mathrm{SeV}+$ & $124 / 224(55.4)$ & 75/100 (75) & $16 / 66(24.2)$ & $5 / 8(62.5)$ \\
\hline & $\mathrm{SeV}-$ & $0 / 260$ & 0/110 & $0 / 95$ & $0 / 13$ \\
\hline
\end{tabular}

$\mathrm{SeV}+$ : transfected by SeV-GFP. SeV-: control.

Numbers of colonies per 2000 cells.

distribution of transduced $\mathrm{CB} \mathrm{CD}^{+} 4^{+}$cells in each subcompartment of the cell cycle. Cell cycle fractionation was defined by three-color flow-cytometric analysis of transduced $\mathrm{CB}$ CD $34^{+}$cells stained with 7-AAD and Ki67 . We found that GFP was expressed in all phases of the cell cycle: $22.64 \pm 6.12 \%$ of $\mathrm{G}_{0}, 78.32 \pm 6.83 \%$ of $\mathrm{G}_{1}$, and $83.05 \pm 2.73 \%$ of $S / G_{2} / M$ CB cells (Figure $3 a$ ). Similar results were obtained in $\mathrm{CB} C \mathrm{CD} 34^{+}$cells treated with aphidicolin (Figure 3b).

Effect of SeV-mediated gene transfer on HSCs proliferation. To evaluate the proliferative activity of transduced $\mathrm{CB} \mathrm{CD}^{+} 4^{+}$cells, short-term liquid cultures were observed after exposure to the $\mathrm{SeV}$ vector. As shown in Figure $4 \mathrm{a}$, the growth of $\mathrm{CB} \mathrm{CD} 34^{+}$cells exposed to the $\mathrm{SeV}$ vector was dose-dependently inhibited with no significant difference among $\mathrm{MOI}=5$, 10 and 100. When cell viabilities on days 2, 6 and 10 were compared between SeV-treated and control CB CD34 ${ }^{+}$ cells, SeV-treated cells showed the lowest viability on day 6 (Figure $4 \mathrm{~b}$ ). Annexin V-positive rates of CB CD34+ cells treated with $\mathrm{SeV}$ at $\mathrm{MOI}=10$ and control $\mathrm{CB} \mathrm{CD} 34^{+}$ cells were $10 \%$ and $2 \%$ respectively, on day 4 (data not shown). Absolute numbers of four subpopulations $\left(\mathrm{CD}_{3} 4^{+} \mathrm{GFP}^{+}, \mathrm{CD}^{+} 4^{+} \mathrm{GFP}^{-}, \mathrm{CD} 34^{-\mathrm{GFP}^{+}}\right.$and $\mathrm{CD} 34^{-} \mathrm{GFP}^{-}$ cells) in SeV-treated CB CD34 ${ }^{+}$cells at days 2, 6 and 10
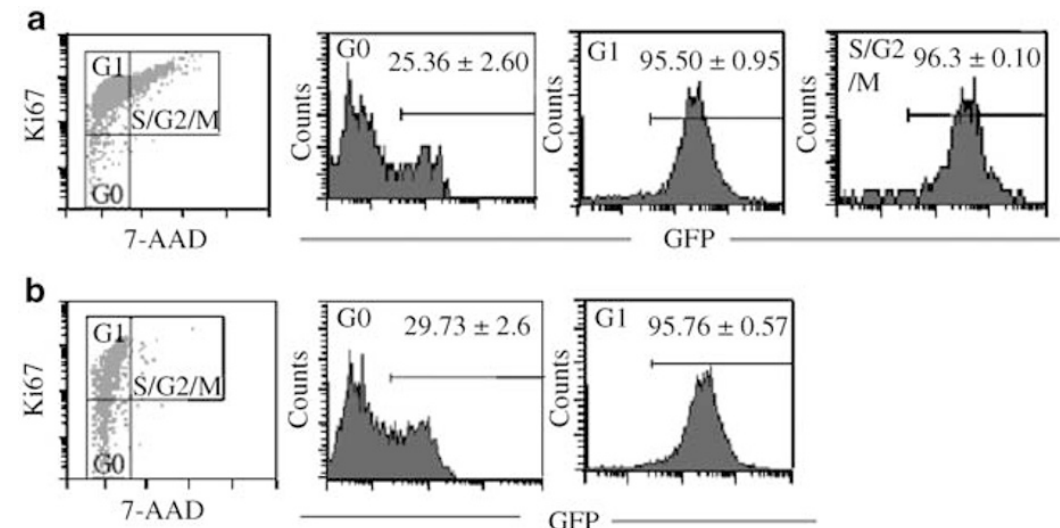

Figure 3 Relationship between cell cycle status and efficiency of transduction with $\mathrm{SeV}$. The percentages of cells with $G F P$ expression in $G_{0}, G_{1}$, and $S / G_{2} /$ $M$ phases of the cell cycle are shown as mean \pm standard deviation values. A representative flow-cytometric data from three experiments is presented: (a) No treatment; (b) progression of transduced cells from G1/S boundary to $S$ phase was blocked by aphidicolin treatment. 

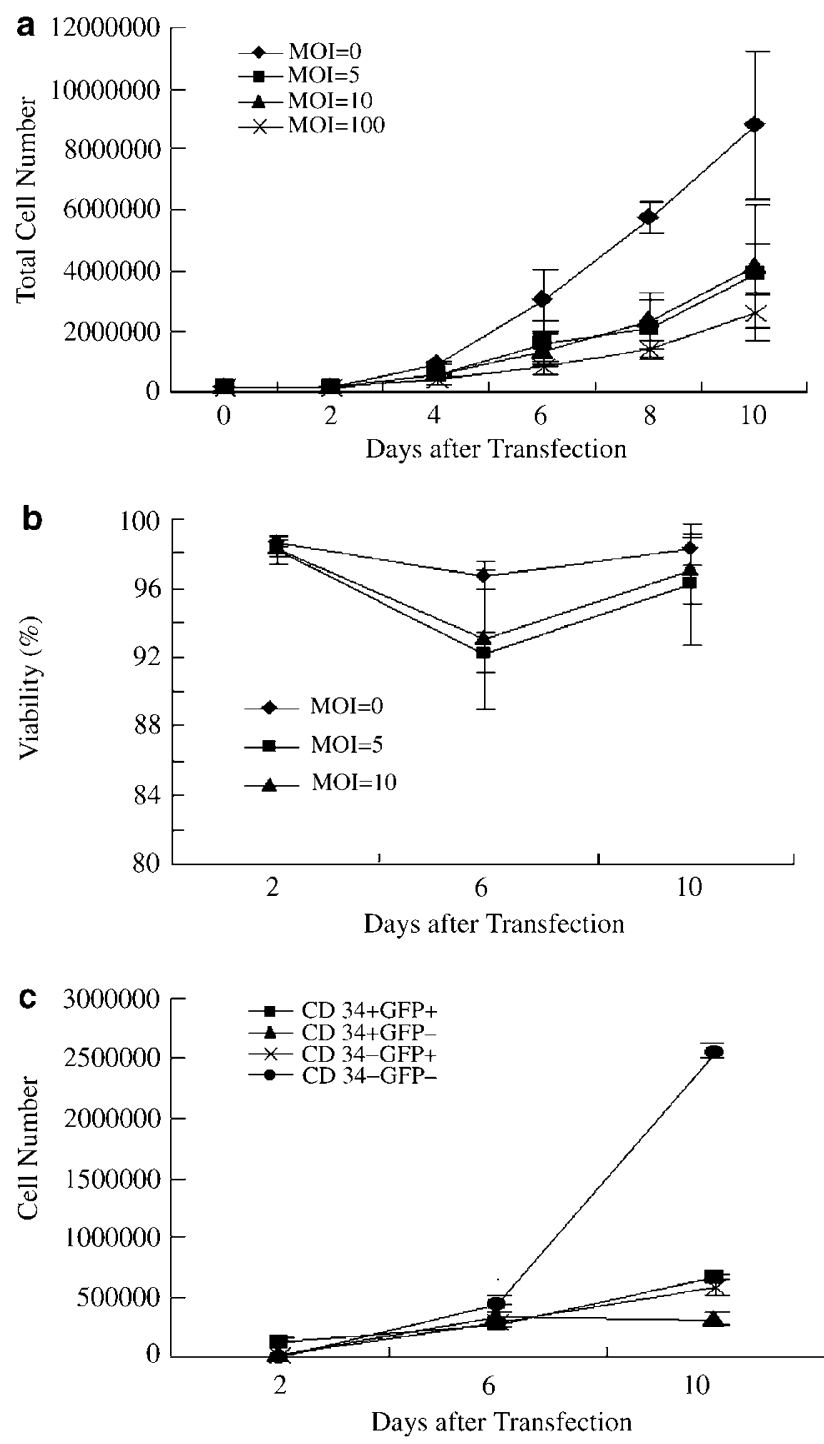

Figure 4 Effect of SeV infection on the proliferative activity of cord blood $C D 34^{+}$cells. CD $34^{+}$cells were transduced with GFP gene by SeV vector at titers 0, 5, 10 and 100 MOIs: (a) the total cell number; (b) viability $(M O I=0,5,10)$ and (c) absolute number of four subpopulations $\left(\mathrm{CD}^{+} 4^{+} \mathrm{GFP}^{+}, \mathrm{CD}^{2} 4^{+} \mathrm{GFP} \mathrm{P}^{-}, \mathrm{CD} 34^{-} \mathrm{GFP}^{+}\right.$and $\mathrm{CD} 34^{-} \mathrm{GFP} \mathrm{P}^{-}$cells $)$were counted at each time point $(M O I=10)$. Data from four cord blood samples, each in triplicate, are shown as mean \pm standard deviation values.

are shown in Figure 4c. Although the proliferation of CD34-GFP- cells was prominent, $\mathrm{CD}^{-} 4^{+} \mathrm{GFP}^{+}$cells continued to grow during the culture period.

\section{Discussion}

In the present study, we demonstrated that $\mathrm{SeV}$ vector efficiently transferred the GFP gene to $\mathrm{CD} 34^{+}$cell and CD $34^{+}$cell subpopulations derived from CB (Figures 1a and $b$ ). Transduction efficiency was not seriously affected by the cell cycle status of the CB. In addition, efficient and stable gene expression was observed in clonogenic erythroid, myeloid or mixed progenitor cells (Figure 2 and Table 1). These data show the efficient gene transfer potential of $\mathrm{SeV}$ to quiescent cells as well as dividing cells, including HSCs and various differentiated hematopoietic lineages.

Non-dividing $\mathrm{CD}_{34}{ }^{+}$cells are considered to include the most long-term subsets of HSCs. ${ }^{7}$ The quiescent stage of $\mathrm{CD}^{+} 4^{+}$cells is important because induction of cell proliferation is associated with a loss of the potential to reconstitute hematopoiesis and with changes in the expression of cellular receptors. ${ }^{8-10}$ In this regard, application of retroviruses to HSCs is limited, because efficient gene transfer is only seen in actively replicating target cells. In a retrovirus system, the fraction of dividing cells needs to be expanded before transduction by prestimulation with cytokines in order to increase the transduction efficiency of HSCs up to $40 \% .^{11-13}$ In the present study, we found that efficient gene transfer with $\mathrm{SeV}(>80 \%)$ was attained without prestimulation of $\mathrm{CD}^{+} 4^{+}$cells with cytokines (Figure 1a). Furthermore, the high expression of the GFP gene (25\%) in $\mathrm{G}_{0}$ compartment of $\mathrm{CD}_{3} 4^{+}$cells seen with $\mathrm{SeV}$-mediated gene transduction (Figures $3 a$ and b) was comparable to that noted in lentivirus-mediated gene transfer. ${ }^{14}$ These results suggest that resting progenitors, long-term culture-initiating cells (LTC-IC) and SCID-repopulating cell (SRC), are easily transduced by the $\mathrm{SeV}$ vector with minimal loss of their potential to repopulate, because they are highly enriched in the $\mathrm{G}_{0}$ compartment. ${ }^{7,}{ }^{15} \mathrm{In}$ this regard, the $\mathrm{SeV}$ vector is a suitable vehicle for transferring genes into HSCs.

From a clinical point of view, in contrast to retrovirus and lentivirus vectors, SeV-mediated gene transfer to $\mathrm{CB}$ $\mathrm{CD} 34^{+}$cells requires only simple procedures. As shown in Figure 1c, CD $34^{+}$cells were efficiently transduced by simply adding $\mathrm{SeV}$ vector solutions at the titer of MOI=10 with only brief contact time, as noted with other cell types. ${ }^{1,2}$ This simplicity in gene transfer procedures using $\mathrm{SeV}$ is also advantageous for clinical application to CB HSCs with their capacity to reconstitute the entire hematopoietic system.

The potential cytotoxicity of SeV to the target cell remains to be a concern, because $\mathrm{SeV}$ induces cytopathic effects in some cells, including CV-1 cells. ${ }^{16}$ In the present study, growth inhibition of transduced $\mathrm{CD} 34^{+}$cells was observed in our short-time liquid suspension culture. Since SeV-induced apoptosis might be possible in some permissive cells through activation of caspase 3 and caspase 8,17 we here assessed the accumulation of annexin V. As the annexin V-positive rate of SeV-treated $\mathrm{CD}^{+} 4^{+}$cells $(10 \%)$ was higher than that of control CD34 ${ }^{+}$ cells $(2 \%)$ on day 4 and SeV-treated cells showed the lowest viability on day 6 (Figure $4 \mathrm{~b}$ ), the induction of apoptosis appears to contribute, probably in part, to decreased cell number. To minimize the damage of transduced cells, development of an $\mathrm{SeV}$ vector lacking cytotoxicity-associated genes such as $\mathrm{C}$ gene might be needed. In contrast, the formation of progenitor colonies, such as GM-CFU, BFU-E and Mix-CFU, in semi-solid culture was not significantly affected after transduction with $\mathrm{SeV}$ (Figure 2 and Table 1). The discrepancy may be explained by the possibility that $\mathrm{CD}_{3}{ }^{+}$cells infected with $\mathrm{SeV}$ at the very early stage of hematopoietic differentiation was less sensitive to growth inhibition than those infected thereafter. Therefore, it is necessary to evaluate in vivo survival, proliferation and transgene expression of $\mathrm{CB} \mathrm{CD} 34^{+}$cells transduced with SeV. 
In summary, although further in vivo reconstruction studies are needed, the $\mathrm{SeV}$ vector is an important candidate for gene transfer to HSCs due to its potential for superior gene transfer into HSCs.

\section{Materials and methods}

\section{Construction of SeV-GFP}

SeV-GFP was constructed, as described. ${ }^{18,19}$ In brief, $18 \mathrm{bp}$ of spacer sequence $5^{\prime}-(\mathrm{G})$-CGGCCGCAGATCTTCACG-3' with a NotI restriction site were inserted between the $5^{\prime}$ non-translated region and the initiation codon of the nucleoprotein $(\mathrm{N})$ gene. This cloned $\mathrm{SeV}$ genome also contains a self-cleaving ribosome site from the antigenomic strand of the hepatitis delta virus. The entire cDNA coding jelly fish enhanced GFP was amplified by PCR, using primers with a NotI site and new sets of $\mathrm{SeV} E$ and $S$ signal sequence tags for an exogenous gene, then inserted into the NotI site of the cloned genome. The entire length of the template $\mathrm{SeV}$ genome, including exogenous genes, was arranged in multiples of six nucleotides (the so-called 'rule of six'). ${ }^{20}$ Template $\mathrm{SeV}$ genome with an exogenous gene and plasmids encoding N, P, and L proteins (plasmid pGEM$\mathrm{N}$, pGEM-P, and pGEM-L) was complexed with commercially available cationic lipids, then cotransfected with vaccinia virus vT7-3 into CV-1 or LLMCK cells. ${ }^{21}$ Forty hours later, the cells were disrupted by three cycles of freezing and thawing and injected into the chorioallantoic cavity of 10-day-old embryonated chicken eggs. Subsequently, the virus was recovered and the vaccinia virus was eliminated by a second propagation in eggs. Virus titer was determined by hemagglutination assay, using chicken red blood cells, ${ }^{22}$ and the virus was stored at $-80^{\circ} \mathrm{C}$ until use.

\section{CB cells samples}

Heparinized CB samples were obtained from umbilical cord veins of four full-term human newborns without hereditary disorders or hematological abnormalities and were analyzed within $24 \mathrm{~h}$. All samples were collected after written informed consent was obtained from the parents.

\section{$C D 34^{+}$cell selection and gene transfer}

CB CD34 cells were labeled with hapten-conjugated monoclonal antibodies (mAbs) against human CD34 (clone QBEnd/10), followed by an anti-hapten antibodies (Abs) coupled with microbeads. The bead-positive cells (CD34 cells) were enriched on positive-selection columns set in a magnetic field. Flow-cytometric analysis of purified cells using a different clone of FITCconjugated anti-CD34 mAb showed more than 95\% purity. Purified CD34 ${ }^{+}$cells were then suspended at 2 to $4 \times 10^{5}$ cells $/ \mathrm{ml}$ in $2.5-\mathrm{cm}$ tissue culture dishes in serum-free Iscove's Modified Dulbecco's medium (IMDM) containing 30\% fetal bovine serum (FBS), 10 $\mathrm{ng} / \mathrm{ml}$ of stem cell factor (SCF, Kirin Brewery Company, Tokyo, Japan), interleukin 6 (IL-6, Kirin Brewery Co), and thrombopoietin (TPO, Kirin Brewery Co). In all experiments, gene transfer was carried out by adding various amounts of vector solution to the media. Cells were then incubated at $37^{\circ} \mathrm{C}$ in a $5 \% \mathrm{CO}_{2}$ incubator, and collected for cell count and flow-cytometric analysis at different time points, as indicated in Figures 1 and 4 . To evaluate the effect of vector exposure time on SeV-mediated gene transfer, cells were washed twice with fresh media after treatment with $\mathrm{SeV}$ at $\mathrm{MOI}=10$. Except for this experiment, the washing after transduction was omitted for purposes of simplification.

\section{Colony assays}

To determine the number of erythroid, myeloid, mixed lineage progenitors, 2000 of the transduced cells were plated in 35-mm tissue culture dishes containing $1 \mathrm{~mL}$ of $0.88 \%$. methylcellulose-based semi-solid culture medium supplemented with $30 \%$ FBS, $50 \mathrm{U} / \mathrm{ml}$ of interleukin 3 (IL-3, Kirin Brewery Co.), $50 \mathrm{ng} / \mathrm{ml}$ of SCF, $50 \mathrm{ng} / \mathrm{ml}$ of granulocyte-macrophage-colony-stimulating factor (GMCSF, Kirin Brewery Co.), and $10 \mathrm{U} / \mathrm{ml}$ of erythropoietin (EPO, Kirin Brewery Co.). After 14 days of incubation at $37^{\circ} \mathrm{C}$ in a $5 \% \quad \mathrm{CO}_{2}$ incubator, colony-forming unitsgranulocyte-macrophage (CFU-GM), burst-forming units-erythroid (BFU-E), colony-forming units-granulocyte erythrocyte monocyte macrophage (CFU-Mix) colonies were enumerated and GFP-expressing colonies were identified, using a fluorescence microscope.

\section{Flow-cytometric analysis}

Transduced cells were stained with appropriate amounts of phycoerythrin (PE)- and phycoerythrin 5.1(PC-5)conjugated $\mathrm{mAbs}$ at $4^{\circ} \mathrm{C}$ for $20 \mathrm{~min}$. All mAbs were obtained from Coulter-Immunotech (Miami, FL, USA). The cells were washed twice and suspended in phosphate-buffered saline (PBS). Flow-cytometric analysis was done using EPICS XL (Beckman-Coulter, Hialeah, FL, USA). A total of at least 10000 events were analyzed for each sample. Gates were set according to forward and side scatters. Cell viability and annexin V-positive rate were assessed by 7-AAD staining and by annexin V-FITC (MBL, Nagoya, Japan) staining, respectively.

For cell cycle analysis, cells were analyzed for Ki-67 expression and DNA content as described by Jordan et $a l^{23}$ but with minor modifications. Briefly, cells incubated at $37^{\circ} \mathrm{C}$ in a $5 \% \mathrm{CO}_{2}$ incubator for $48 \mathrm{~h}$ after transduction were washed and resuspended in 1-ml PBS containing $0.4 \%$ formaldehyde. After $30 \mathrm{~min}$ incubation at $4^{\circ} \mathrm{C}, 1 \mathrm{ml}$ of PBS containing $0.2 \%$ Triton X-100 was added and cells were left overnight at $4^{\circ} \mathrm{C}$. Cells were then washed twice in PBS containing $1 \%$ bovine serum albumin (BSA) and stained with PE-conjugated anti-Ki-67 (clone MIB-1; Immunotech, West-brook, ME, USA) for $60 \mathrm{~min}$ at $4^{\circ} \mathrm{C}$. Isotype-matched $\mathrm{mAb}$ control was used in parallel. Finally, cells were washed and resuspended in PBS containing $1 \%$ BSA and $5 \mu \mathrm{g} / \mathrm{ml} 7$-aminoactinomycin-D (7-AAD; Sigma). After $3 \mathrm{~h}$ of incubation on ice, samples were run on flow cytometer using FL-1 and FL-2 channels for Ki-67 and 7-AAD, respectively. To block the cells at G1/S boundary, transduced cells were treated with $2 \mathrm{mg} / \mathrm{ml}$ of aphidicolin (Sigma Chemical Co, St Louis, $\mathrm{MO}, \mathrm{USA}$ ) at $37^{\circ} \mathrm{C}$ in a $5 \% \mathrm{CO}_{2}$ incubator for $48 \mathrm{~h}$.

\section{Acknowledgements}

We thank Dr Kusuo Sanada for providing cord blood samples. This study was supported by a Grant of Promotion of Basic Scientific Research in Medical Frontier of the Organization for Pharmaceutical Safety 
and Research, and by a Grant-in-Aid for Scientific Research from the Ministry of Education, Culture, Sports, Science and Technology of Japan. M Ohara provided language assistance.

\section{References}

1 Yonemitsu $Y$ et al. Efficient gene transfer to airway epithelium using recombinant Sendai virus. Nat Biotechnol 2000; 18: 970-973.

2 Masaki I et al. Recombinant Sendai virus-mediated gene transfer to vasculature: a new class of efficient gene transfer vector to the vascular system. FASEB J 2001; 15: 1294-1296.

3 Shiotani A et al. Skeletal muscle regeneration after insulin-like growth factor I gene transfer by recombinant Sendai virus vector. Gene Ther 2001; 8: 1043-1050.

4 Yamashita A et al. Fibroblast growth factor-2 determines severity of joint disease in adjuvant-induced arthritis in rats. I Immunol 2002; 168: 450-457.

5 Markwell MA, Svennerholm L, Paulson JC. Specific gangliosides function as host cell receptors for Sendai virus. Proc Natl Acad Sci USA 1981; 78: 5406-5410.

6 Moyer SA, Baker SC, Lessard JL. Tubulin: a factor necessary for the synthesis of both Sendai virus and vesicular stomatitis virus RNAs. Proc Natl Acad Sci USA 1986; 83: 5405-5409.

7 Gothot A et al. Assessment of proliferative and colony-forming capacity after successive in vitro divisions of single human CD34+ cells initially isolated in $\mathrm{G}_{0}$. Exp Hematol 1998; 26: 562570 .

8 Becker PS et al. Adhesion receptor expression by hematopoietic cell lines and murine progenitors: modulation by cytokines and cell cycle status. Exp Hematol 1999; 27: 533-541.

9 Gonzalez $\mathrm{R}$ et al. Increased gene transfer in acute myeloid leukemic cells by an adenovirus vector containing a modified fiber protein. Gene Ther 1999; 6: 314-320.

10 Huang S, Endo RI, Nemerow GR. Upregulation of integrins alpha $\mathrm{v}$ beta 3 and alpha $\mathrm{v}$ beta 5 on human monocytes and lymphocytes facilitates adenovirus-mediated gene delivery. $J$ Virol 1995; 69: 2257-2263.

11 Bodine DM, McDonagh KT, Seidel NE, Nienhuis AW. Survival and retrovirus infection of murine hematopoietic stem cells in vitro: effects of 5-FU and method of infection. Exp Hematol 1991; 19: 206-212.

12 Tumas DB et al. High-frequency cell surface expression of a foreign protein in murine hematopoietic stem cells using a new retroviral vector. Blood 1996; 87: 509-517.

13 Cavazzana-Calvo $\mathrm{M}$ et al. Gene therapy of human severe combined immunodeficiency (SCID)-X1 disease. Science 2000; 28: 669-672.

14 Luther-Wyrsch A et al. Stable transduction with lentiviral vectors and amplification of immature hematopoietic progenitors from cord blood of preterm human fetuses. Hum Gene Ther 2001; 12: 377-389.

15 Gothot A et al. Cell cycle-related changes in repopulating capacity of human mobilized peripheral blood CD $34^{+}$cells in non-obese diabetic/severe combined immune-deficient mice. Blood 1998; 92: 2641-2649.

16 Kato A et al. The paramyxovirus, Sendai virus, V protein encodes a luxury function required for viral pathogenesis. EMBO J 1997; 16: 578-587.

17 Bitzer $\mathrm{M}$ et al. Sendai virus infection induces apoptosis through activation of caspase-8 (FLICE) and caspase-3 (CPP32). J Virol 1999; 73: 702-708.

18 Kato A et al. Initiation of Sendai virus multiplication from transfected cDNA or RNA with negative or positive sense. Genes Cells 1996; 1: 569-579.

19 Sakai $Y$ et al. Accommodation of foreign genes into the Sendai virus genome: sizes of inserted genes and viral replication. FEBS Lett 1999; 456: 221-226.

20 Kolakofsky D et al. Paramyxovirus RNA synthesis and the requirement for hexamer genome length: the rule of six revisited. J Virol 1998; 7: 891-899.

21 Fuerst TR, Niles EG, Studier FW, Moss B. Eukaryotic transientexpression system based on recombinant vaccinia virus that synthesizes bacteriophage T7 RNA polymerase. Proc Natl Acad Sci USA 1986; 83: 8122-8126.

22 Yonemitsu Y, Kaneda Y. Hemagglutinating virus of Japanliposome-mediated gene delivery to vascular cells. In: Baker AH (ed.). Molecular Biology of Vascular Diseases. Methods in Molecular Medicine. Humana Press: Clifton, 1999, pp 295-306.

23 Jordan CT, Yamasaki G, Minamoto D. High-resolution cell cycle analysis of defined phenotypic subsets within primitive human hematopoietic cell populations. Exp Hematol 1996; 24: 1347-1355. 